\title{
Highly Crosslinked-remelted versus Less-crosslinked Polyethylene in Posterior Cruciate-retaining TKAs in the Same Patients
}

\author{
Young-Hoo Kim MD, Jang-Won Park MD, Jun-Shik Kim MD, \\ June-Hyung Lee MD
}

Received: 16 March 2015/Accepted: 19 June 2015/Published online: 27 June 2015

(C) The Association of Bone and Joint Surgeons(B 2015

\begin{abstract}
Background Concern regarding osteolysis attributable to polyethylene wear after TKA, particularly in younger patients, has prompted the introduction of highly crosslinkedremelted polyethylene (HXLPE) for TKAs. However, few in vivo comparative results of TKAs using HXLPE and less-crosslinked polyethylene inserts in the same patients are available, regarding fracture or failure of the locking mechanism of tibial polyethylene inserts or of osteolysis in patients younger than 60 years.

Questions/Purposes We wanted to determine whether (1) survivorship free from aseptic loosening in knees with HXLPE inserts was different from survivorship in knees with less-crosslinked polyethylene inserts, (2) the prevalence of fracture or failure of the locking mechanism of the
\end{abstract}

Each author certifies that he or she, or a member of his or her immediate family, has no funding or commercial associations (eg, consultancies, stock ownership, equity interest, patent/licensing arrangements, etc) that might pose a conflict of interest in connection with the submitted article.

All ICMJE Conflict of Interest Forms for authors and Clinical Orthopaedics and Related Research ${ }^{\mathbb{R}}$ editors and board members are on file with the publication and can be viewed on request.

Clinical Orthopaedics and Related Research ${ }^{\circledR}$ neither advocates nor endorses the use of any treatment, drug, or device. Readers are encouraged to always seek additional information, including FDA approval status, of any drug or device before clinical use. Each author certifies that his or her institution approved the human protocol for this investigation, and that all investigations were conducted in conformity with ethical principles of research, and that informed consent for participation in the study was obtained.

Y.-H. Kim ( $\varangle)$, J.-W. Park, J.-S. Kim, J.-H. Lee

The Joint Replacement Center, MokDong Hospital, Ewha

Womans University School of Medicine, 911-1, MokDong,

YangChun-Ku, Seoul 158-710, Republic of Korea

e-mail: younghookim@ewha.ac.kr tibial polyethylene insert was greater in knees with HXLPE than in those with less-crosslinked polyethylene, and (3) the proportion of patients who had osteolysis develop was greater with HXLPE than with less-crosslinked polyethylene inserts.

Methods One hundred seventy-one patients with a mean age of $58 \pm 8$ years (range, 35-59 years) received posterior cruciate-retaining prostheses with a less-crosslinked polyethylene tibial insert in one knee and a HXLPE tibial insert in the contralateral knee. From January 2007 to January 2010, we performed 366 same-day bilateral simultaneous sequential posterior cruciate-retaining TKAs in 183 patients, of whom 171 (93\%) participated in this study. All patients during this study period underwent posterior cruciate-retaining TKAs regardless of deformity of the knees and we did not perform posterior-stabilized TKAs during the same period. Patients who had bilateral end-stage osteoarthritis and were younger than 60 years were selected for inclusion. Six patients (4\%) were lost to followup before 5 years. Twenty-six patients were males and 145 were females. The mean duration of followup was 6 years (range, 5-8 years). At each followup, patients were assessed for loosening of the components, fracture or failure of the locking mechanism of the polyethylene inserts, or osteolysis.

Results The survival rate of the knee prosthesis at a mean of 5.8 years after surgery was $100 \%$ (95\% CI, $0.95-1.00)$ in both groups for the endpoint aseptic loosening and $99.4 \%$ (95\% CI, 0.95-1.00) in both groups for the endpoint revision. No knee in either group had fracture or failure of the locking mechanism of the tibial polyethylene insert, and none had osteolysis.

Conclusions With the numbers available, we found no clinically important differences between HXLPE and lesscrosslinked polyethylene inserts in posterior cruciate- 
retaining TKAs. Given that HXLPE is newer, as-yet unproven, and more expensive than the proven technology (less-crosslinked polyethylene), we suggest not adopting HXLPE for clinical use until it shows superiority.

Level of Evidence Level I, therapeutic study.

\section{Introduction}

Although TKAs have provided durable, long-term results $[16,18,28]$, some patients experience polyethylene wear and osteolysis 5 to 12 years after surgery [3, 6, 11, 13, 23-26, 30,32 ]. Collier et al. [5] suggested that polyethylene wear is a major risk factor affecting long-term survival of TKA implants. Concern regarding development of osteolysis attributable to polyethylene wear, particularly in younger patients, prompted the introduction of highly crosslinked, remelted polyethylene (HXLPE) to prevent or minimize prospective oxidative degradation of the material [22].

The enhanced resistance of HXLPE to particulate burnishing-type wear comes at the expense of some tradeoffs [21]. Studies of HXLPE bearings have detected a higherthan-ordinary percentage of wear particles smaller than 1 $\mu \mathrm{m}$, and these particles could induce relatively more inflammation or osteolysis at a given volume of polyethylene debris [7]. Use of HXLPE in TKAs could increase the risk of fracture of the tibial polyethylene insert at an articular or nonarticular region given the lower material toughness that stems from more polymer crosslinks [1719]. However, the polyethylene of these HXLPE implants customarily is treated to make the material more resistant to mechanical failure secondary to oxidative degradation [14, 17, 19].

Several studies presented in vivo clinical results of TKAs using HXLPE in elderly patients [8, 15, 20]. Hodrick et al. [8] reported that the clinical and radiographic results were better in the HXLPE group after 6 years followup. Minoda et al. [20] reported that the clinical and radiographic results were not different between the two groups after 2 years followup. Long et al. [15] and Kim and Park [12] reported patient-reported outcomes of posterior cruciate-substituting TKAs were satisfactory in both groups. No fractures or failures of the locking mechanism of the tibial insert and no osteolysis in the knees with HXLPE were seen $[8,12,15,20]$. To our knowledge, there are no published studies of in vivo comparative clinical results of posterior cruciate-retaining TKAs using HXLPE and lesscrosslinked polyethylene inserts regarding fracture or failure of the locking mechanism of tibial polyethylene inserts or osteolysis in patients younger than 60 years. It has been reported that in posterior cruciate-retaining TKAs, a paradoxic roll-forward of the femur with anterior translation of the tibiofemoral contact area and femoral condylar lift-off were more commonly observed [30], which potentially leads to increased wear and failure of the locking mechanism of tibial polyethylene inserts.

The purposes of our study therefore were to determine whether (1) survivorship free from aseptic loosening in the knees with HXLPE inserts was different from those associated with less-crosslinked polyethylene inserts, (2) the prevalence of fracture or failure of the locking mechanism of the tibial polyethylene insert was greater in the knees with HXLPE than in knees with less-crosslinked polyethylene, and (3) the proportion of patients who have osteolysis develop was greater with HXLPE inserts than with less-crosslinked polyethylene inserts.

\section{Patients and Methods}

From January 2007 to January 2010, we prospectively enrolled 183 patients (366 knees) younger than 60 years with bilateral end-stage osteoarthritis of the knee who underwent bilateral simultaneous sequential TKAs during the same anesthesia session. All patients during this study period underwent posterior cruciate-retaining TKAs regardless of deformity of the knees. The study protocol and consent forms were approved by the institutional review board. A detailed informed-consent form was signed by each patient. Six patients dropped out after enrollment and six others were lost to followup at 1 year, leaving 171 patients (342 knees) available for study at a minimum of 5 years (mean, 6 years; range, 5-8 years) (Fig. 1).

The study group included 145 women and 26 men with a mean age of $58 \pm 8$ years (range, 35-59 years) at the time of surgery. The high percentage of women presumably was attributable to the preponderance of severe primary osteoarthritis of the knee in females. The mean BMI of the patients was $26 \mathrm{~kg} / \mathrm{m}^{2}$ (range, 25-39 kg/m ${ }^{2}$ ). Varus and valgus alignments of the knee were determined using anatomic axes of the femur and tibia on standing hip-toankle AP radiographs. Forty-five (13\%) of the 342 knees had varus alignment of $3^{\circ}$ to $5^{\circ}$ and the remaining 297 knees $(87 \%)$ had varus alignment of $6^{\circ}$ to $25^{\circ}$. Twenty-two (13\%) patients in the HXLPE group and 26 (15\%) of 171 patients in the less-crosslinked polyethylene group had undergone previous arthroscopic débridement; the remaining patients had no previous surgery of their knees.

Randomization of the Gender Solutions ${ }^{\circledR}$ NexGen ${ }^{\circledR}$ posterior cruciate-retaining high flexion prosthesis (Zimmer, Warsaw, IN, USA) to be used with a HXLPE bearing (Prolong ${ }^{\circledR}$; Zimmer) or a less-crosslinked polyethylene bearing (Zimmer) was done using a study number in a sealed envelope. The envelope was opened in the operating room, before the skin incision was made, and the first knee 


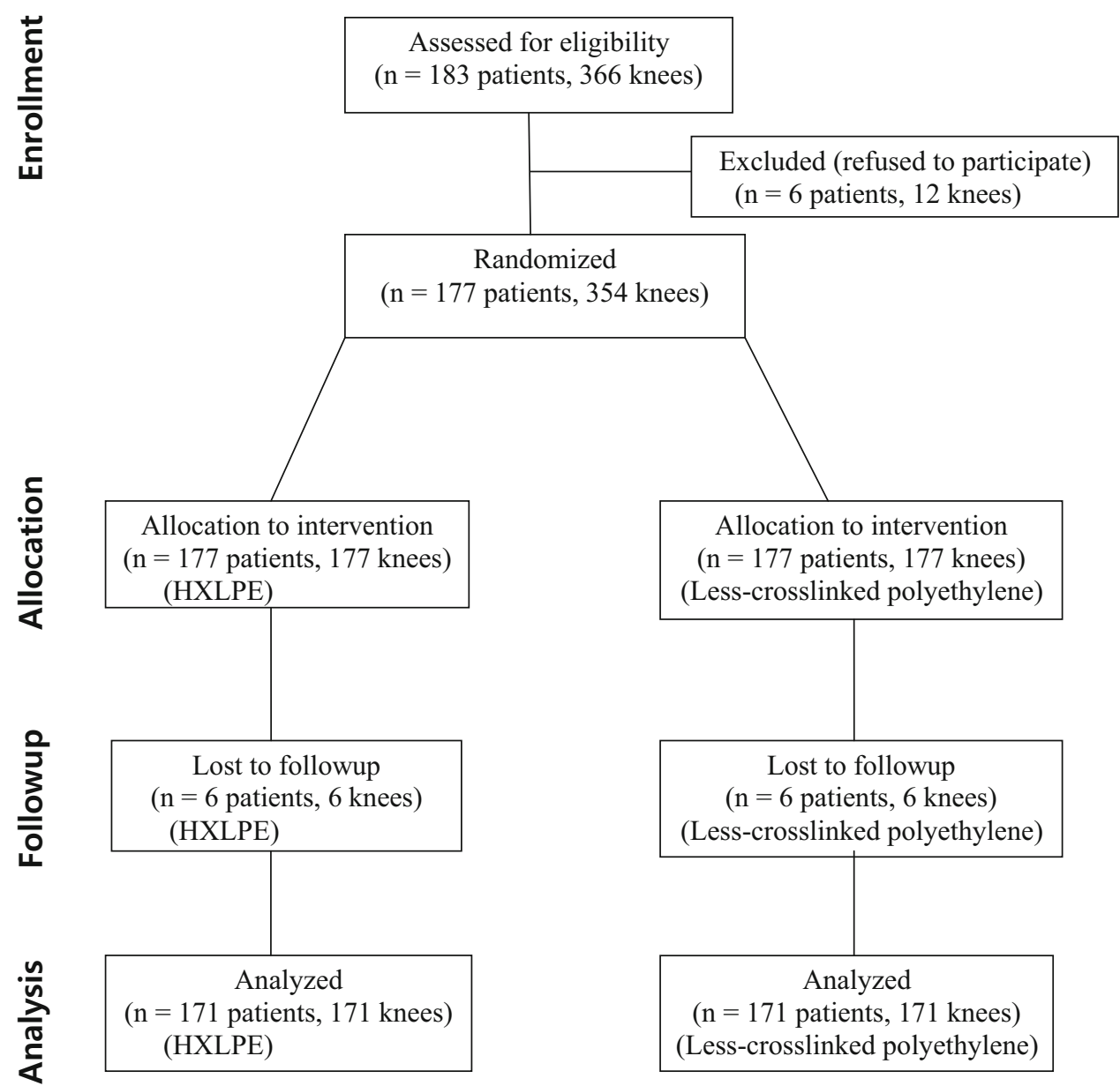

Fig. 1 The study diagram is shown. Bilateral TKAs were performed in 354 knees in 177 patients using a Gender Solutions ${ }^{\mathbb{R}}$ NexGen ${ }^{\mathbb{R}}$ High Flex cruciate-retaining prosthesis. Each patient had a lesscrosslinked polyethylene implanted in one knee and a HXLPE

was assigned to receive the tibial insert indicated by the number in the envelope and the contralateral knee received the other tibial insert. The design and materials of the femoral component (cobalt-chromium-molybdenum [Co-Cr-Mo] alloy) and tibial component (titanium alloy [Ti-6V-4Al]) were the same in both groups. The average surface roughness (Ra) of the femoral condyle was $3 \mu \mathrm{m}$ and the average surface roughness of the upper tibial baseplate surface was $20 \mu \mathrm{m}$. The design of the polyethylene insert also was the same in both groups, except for the use of either HXLPE or less-crosslinked polyethylene. The less-crosslinked polyethylene bearing was manufactured by net-shape molding of GUR 1050 resin and crosslinked as an offshoot of exposing it to $37 \mathrm{kGy}$ radiation during sterilization and sealed in an air-impermeable assembly containing an inert gas so as to inhibit preimplantation oxidation of the free radicals that are generated during the radiation sterilization. The HXLPE bearing was manufactured by net-shape molding of GUR 1050 resin. implanted in the contralateral knee. One hundred seventy-one patients had a minimum 5-year followup completed for both knees. HXLPE = highly cross-linked polyethylene.

The material of the HXLPE bearing was crosslinked by electron beam radiation at a dose of $65 \mathrm{kGy}$ and subsequently remelted to eliminate free radicals generated during the prior step before the part is machined to final shape. The finished implants ultimately were sterilized using a method that does not generate new free radicals.

All procedures were performed by the senior author (YHK) with tourniquet inflation to $250 \mathrm{~mm} \mathrm{Hg}$. An anterior midline skin incision (10 to $12 \mathrm{~cm}$ in length) was made, followed by a medial parapatellar capsular incision. Tibial bone was resected $10 \mathrm{~mm}$ with a $7^{\circ}$-posterior tibial slope. An anterior cortical reference was used for the AP cut of the distal part of the femur. Femoral component rotation was determined using three reference axes: (1) the transepicondylar axis, (2) the mid-trochlear (Whiteside) line [1], and (3) $3^{\circ}$ external rotation relative to the posterior aspect of the condyles. Ligamentous balance was established first in knee extension and then in knee flexion with use of a tensor. All patellae were resurfaced with 
polyethylene implants. All implants were cemented after pulsed lavage irrigation, drying, and pressurization of vacuum-mixed cement.

On the second postoperative day, patients started active ROM exercises and began using a continuous passive motion machine. All patients were discharged home from the hospital 10 to 14 days after surgery; they were allowed full weightbearing and were advised to use crutches or a walker for 6 weeks. At each followup, radiographic data were analyzed and recorded by a clinical fellow (HKO) who was not part of the surgical team. All clinical data were compiled and collected by a research associate (DRK).

All radiographs were made under fluoroscopic guidance to control rotation of the knee. Osteolysis around the components, fracture of the tibial polyethylene insert, or failure of the locking mechanism of the tibial polyethylene insert was recorded. Aseptic loosening was defined if there was complete continuous radiolucency larger than $1 \mathrm{~mm}$ around the components or position change of the components.

\section{Statistical Analysis}

Nonparametric chi-square tests were used to compare complication rates and radiographic data between the two groups. Using the Bonferroni method [29], the $\alpha$ level of each test was adjusted downward to ensure that the overall results for the number of tests remained at 0.05 . In our study, the $\alpha$ level should have been less than 0.0025 after 19 outcomes measures to reach significance. The level of significance was set at $\mathrm{p}$ less than 0.05. Cumulative survival rates and associated 95\% CIs were calculated using a Kaplan-Meier survival curve [10].

\section{Results}

No knee in either group had aseptic loosening of the femoral, tibial, or patellar component. The survival rate of the knee prosthesis at a mean of 5.8 years after surgery was $100 \%$ (95\% CI, 0.95-1.00) in both insert groups for the endpoint of aseptic loosening, and 99\% (95\% CI, 0.951.00 ) in both groups for the endpoint of revision.

No knee in ether group had a fracture of the tibial polyethylene insert or failure of the locking mechanism of the tibial polyethylene insert, and no osteolysis developed around the knee components in either group (Fig. 2)

\section{Discussion}

Although TKAs have provided durable, long-term results $[16,18]$, some patients experience polyethylene wear and osteolysis 5 to 12 years after surgery $[3,6,11,13,24-26$, 30, 32]. Collier et al. [5] suggested that polyethylene wear is a major risk factor affecting long-term survival of TKA implants. Concern regarding development of osteolysis attributable to polyethylene wear, particularly in young patients, prompted the introduction of HXLPE to prevent or minimize prospective oxidative degradation of the material [22]. Kim and Park [12] compared HXLPE and less-crosslinked polyethylene inserts in posterior cruciatesubstituting TKAs in the same patients and reported that no knee in either group had aseptic loosening, fracture of the tibial polyethylene insert, or failure of the locking mechanism of the tibial polyethylene insert. Stiehl et al. [31] reported that in posterior cruciate-retaining TKAs, a paradoxic roll-forward of the femur with anterior translation of the tibiofemoral contact area and femoral condylar lift off were seen, which potentially increased wear and failure of the locking mechanism of the tibial polyethylene insert. The purposes of our study were to determine whether (1) survivorship free from aseptic loosening of the posterior cruciate-retaining TKA prosthesis with HXLPE inserts was similar to survivorship with less-crosslinked polyethylene inserts; (2) the prevalence of fracture or failure of the locking mechanism of the tibial polyethylene inserts was greater in knees with HXLPE than in those with lesscrosslinked polyethylene; and (3) the proportion of patients who had osteolysis develop was greater with HXLPE inserts than with less-constrained polyethylene inserts.

Our study has some limitations. First, because of the ceiling effects of the knee scores used, our ability was limited to differentiating outcomes between the two groups. Second, the preponderance of female patients $(85 \%)$ with a low BMI $\left(26 \mathrm{~kg} / \mathrm{m}^{2}\right)$ may make the study results not generalizable. Third, considering the very low prevalence of fracture with the tibial polyethylene insert, a larger number of knees in each group may be required to minimize the chance of Type 2 error. Therefore, our study may have been underpowered in terms of its ability to show the prevalence of fractures in tibial polyethylene inserts. Fourth, we had no interobserver variability to ensure consistency in interpreting knee scores and radiographic findings. Fifth, although the study of one type of polyethylene in the right knee and the other type in the left knee of the same patients has advantages, it also has disadvantages in that function is generally an integrated concept that is difficult to assign to individual knees. Sixth, because no patient had more than 8 years followup there was no polyethylene failure or other wear-related complications during the study interval, as those outcomes would not be expected to be seen before that interval with posterior cruciate-retaining prostheses that met 2007 to 2010 standards for devices. Finally, our study was limited to polyethylene bearings of two material types in one articular 

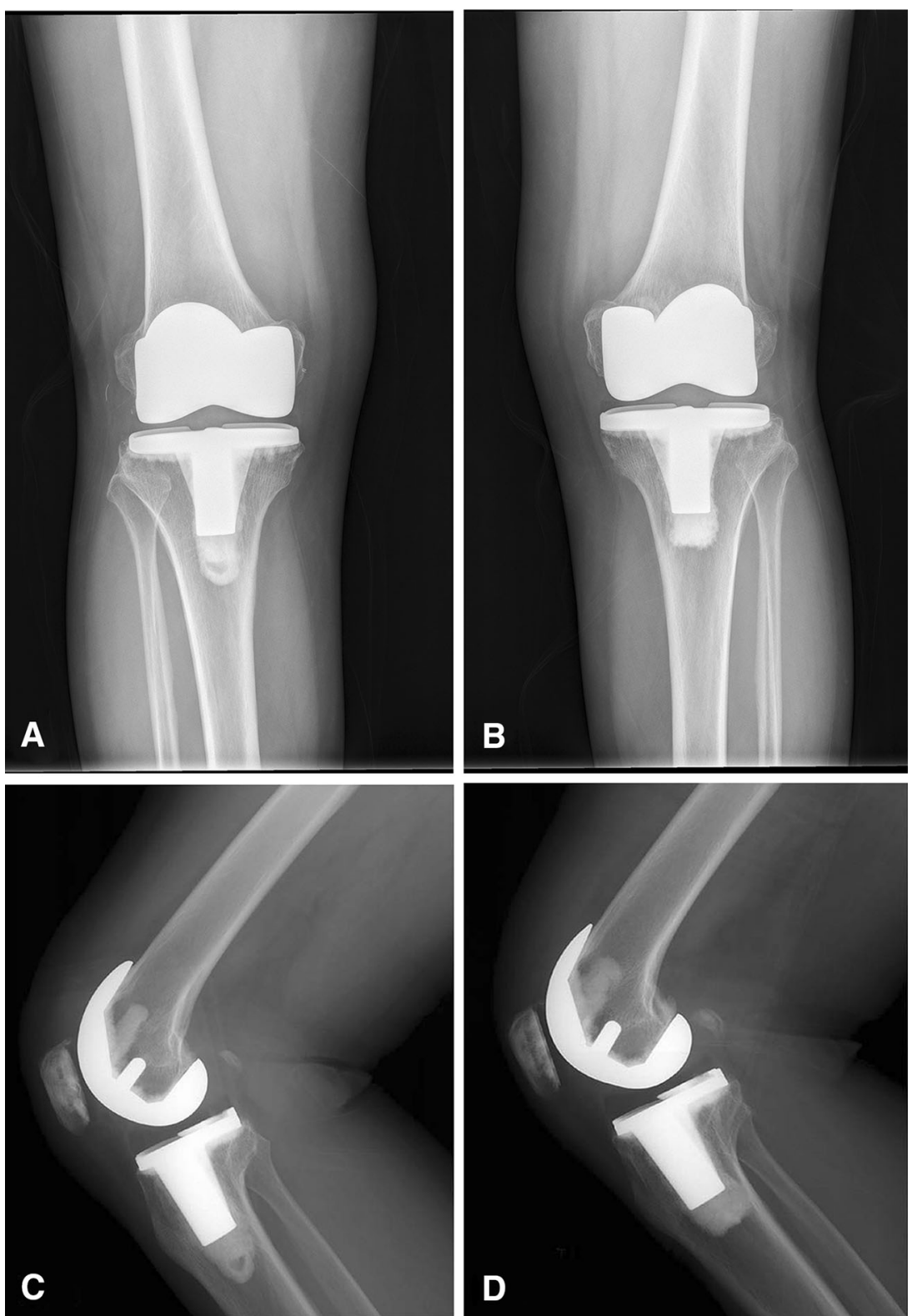

Fig. 2A-D Radiographs of both knees of a 55-year-old woman with end-stage osteoarthritis are shown. AP radiographs of the (A) right knee obtained 8 years after surgery shows that the Gender Solutions ${ }^{\mathbb{R}}$ NexGen ${ }^{\circledR}$ High Flex cruciate-retaining prosthesis with HXLPE and (B) Gender Solutions ${ }^{\circledR}$ NexGen ${ }^{\circledR}$ High Flex cruciate-retaining prosthesis with less-crosslinked polyethylene are fixed rigidly in a satisfactory position. No radiolucent lines or osteolysis were seen

adjacent to the tibial component in either knee, and no gross wear of the polyethylene tibial insert was seen in either knee. Lateral radiographs of the $(\mathbf{C})$ right and (D) left knees show the absence of radiolucent line and osteolysis around the femoral, tibial, and patellar components in both knees. The radiograph of the left knee was flipped for better comparison. HXLPE = highly crosslinked polyethylene.

constraint level and one implant system, therefore our findings may not be generalizable to other implant variations.

Hodrick et al. [8] performed a retrospective study of 100 patients receiving an HXLPE insert and compared them with 100 patients who received less-crosslinked polyethylene tibial inserts. They used the Natural Knee ${ }^{\mathbb{R}}$ II cruciate-retaining TKA system (Zimmer), in which the tibial

components are modular and the base plate is an asymmetric design. The mean ages of their patients were 70 and 67 years old in each group. The length of followup was approximately 6 years in both groups. They observed better radiographic results, in terms of radiolucent lines, osteolysis, and aseptic loosening of the components with the HXLPE inserts. Minoda et al. [20] performed a retrospective review of 83 patients receiving HXLPE inserts and compared them 
with 99 patients who received less-crosslinked polyethylene tibial inserts in the setting of posterior cruciate-retaining TKA prosthesis. The mean ages of patients were 70 and 71 years in each group. The mean length of followup was 2 years in both groups. They found no difference in postoperative clinical scores or radiographic results between the two groups. These previous studies $[8,20]$ did not involve bilateral simultaneous TKAs in the same patients, were retrospective, and the mean followup of the patients in one study [20] was only 2 years. Our study was a prospective randomized study of bilateral simultaneous (sequential) TKAs in the same patients. Kim and Park [12] found no differences in postoperative clinical scores or radiographic results between use of NexGen ${ }^{\circledR}$ posterior cruciate-substituting prostheses with HXLPE and those with lesscrosslinked polyethylene. We found no differences between HXLPE and less-crosslinked polyethylene with respect to survivorship of the components, fracture or failure of the locking mechanism of tibial polyethylene inserts, or osteolysis. These findings support those of Minoda et al. [20] but do not support those of Hodrick et al. [8].

The absence of detectable free radicals has been highlighted as the primary reason for the choice of remelting for HXLPE [21], however, the remelting process causes changes in the morphologic features and lowers the mechanical and fatigue properties [4]. Mechanical and fatigue behavior are even more important for devices used at the knee than the hip because of the high contact stress associated with activities of daily living [2]. A fluoroscopic study by Stiehl et al. [31] showed that posterior cruciateretaining TKA prostheses do not replicate the kinematics of the normal knee. Instead, in many cases a paradoxic rollforward of the femur and femoral condylar liftoff occur. These adverse consequences may increase posterior tibial polyethylene wear or failure of the locking mechanism of the tibial polyethylene insert. Because of these adverse consequences, there were some questions regarding the appropriateness of remelted HXLPE for use in TKAs. Ries and Pruitt [27] concluded that HXLPE should not be used in TKAs. However, Minoda et al. [20] reported no early failures of TKAs using posterior cruciate-retaining prostheses attributable to HXLPE. Additionally Hodrick et al. [8] and Kim and Park [12] reported no mechanical failures or osteolysis attributable to HXLPE. In our series, there were no fractures or failure of the locking mechanism of the tibial polyethylene insert attributable to the newly introduced HXLPE, nor did any patients have osteolysis develop. The preponderance of female patients with light body weight might have contributed to the absence of tibial polyethylene fracture or failure of the tibial polyethylene locking mechanism. The duration of followup was not long enough to document later problems.
Particles generated by HXLPE are smaller than those generated by less-crosslinked polyethylene [7]. These smaller particles are more biologically active and theoretically could lead to a greater incidence of osteolysis [7, 9, 27]. Some authors $[8,12,20]$ found no osteolysis in their series of cruciate-retaining or posterior cruciate-substituting prostheses. In our study, no knee in either group had osteolysis, although the followup was too short to observe osteolysis.

We could not identify an advantage or disadvantage associated with use of either the HXLPE, remelted polyethylene tibial insert in one knee and less-cross linked polyethylene insert in the contralateral knee in our patients with 5 to 8 years followup. Identification of any clinical advantages that might exist in favor of each type of these polyethylene materials would need a study with longer followup. Given that HXLPE is newer, as-yet unproven, and more expensive than the proven technology (lesscrosslinked polyethylene), we suggest not adopting HXLPE for clinical use until it shows superiority.

Acknowledgments The authors express great thanks to Hyun-Keun Oh, MD for his radiographic data analysis and Ms Doo-Ri Kim, BS for her collecting and compiling clinical data at the Joint Replacement Center, Ewha Womans University School of Medicine, Seoul, Republic of Korea.

\section{References}

1. Arima J, Whiteside LA, McCarthy DS, White SE. Femoral rotational alignment, based on the anteroposterior axis, in total knee arthroplasty in a valgus knee: a technical note. J Bone Joint Surg Am. 1995;77:1331-1334.

2. Bartel DL, Rawlinson JJ, Burstein AH, Ranawat CS, Flynn WF Jr. Stresses in polyethylene components of contemporary total knee replacements. Clin Orthop Relat Res. 1995;317:76-82.

3. Cadambi A, Engh GA, Dwyer KA, Vinh TN. Osteolysis of the distal femur after total knee arthroplasty. J Arthroplasty. 1994;9:579-594.

4. Collier JP, Currier BH, Kennedy FE, Currier JH, Timmins GS, Jackson SK, Brewer RL. Comparison of cross-linked polyethylene materials for orthopaedic applications. Clin Orthop Relat Res. 2003;414:289-304.

5. Collier JP, Sperling DK, Currier JH, Sutula LC, Saum KA, Mayor MB. Impact of gamma sterilization on clinical performance of polyethylene in the knee. J Arthroplasty. 1996;11:377-389.

6. Ezzet KA, Garcia R, Barrack RL. Effect of component fixation method on osteolysis in total knee arthroplasty. Clin Orthop Relat Res. 1995;321:86-91.

7. Fisher J, McEwen HM, Tipper JL, Galvin AL, Ingram J, Kamali A, Stone MH, Ingham E. Wear, debris, and biologic activity of cross-linked polyethylene in the knee: benefits and potential concerns. Clin Orthop Relat Res. 2004;428:114-119.

8. Hodrick JT, Severson EP, McAlister DS, Dahl B, Hoffmann AA. Highly crosslinked polyethylene is safe for use in total knee arthroplasty. Clin Orthop Relat Res. 2008;466:2806-2812.

9. Jacobs JJ, Roebuck KA, Archibeck M, Hallab NJ, Glant TT. Osteolysis: basic science. Clin Orthop Relat Res. 2001;393:71-77.

10. Kaplan EL, Meier P. Nonparametric estimation from incomplete observations. J Am Stat Assoc. 1958;53:457-481. 
11. Kim $\mathrm{YH}, \mathrm{Oh} \mathrm{JH}, \mathrm{Oh} \mathrm{SH}$. Osteolysis around cementless porous-coated anatomic knee prostheses. J Bone Joint Surg Br. 1995;77:236-241.

12. Kim YH, Park JW. Comparison of highly cross-linked and conventional polyethylene in posterior cruciate-substituting total knee arthroplasty in the same patients. J Bone Joint Surg Am. 2014;96:1807-1813.

13. Kurtz S, Ong K, Lau E, Mowat F, Halpern M. Projections of primary and revision hip and knee arthroplasty in the United States from 2005 to 2030. J Bone Joint Surg Am. 2007;89:780-785.

14. Lombardi AV Jr, Mallory TH, Fada RA, Adams JB, Kefauver CA. Fracture of the tibial spine of a Total Condylar III knee prosthesis secondary to malrotation of the femoral component. Am J Knee Surg. 2001;14:55-59.

15. Long WJ, Levi GS, Scuderi GR. Highly cross-linked polyethylene in posterior stabilized total knee arthroplasty: early results. Orthop Clin North Am. 2012;43:e35-38.

16. Lutzner J, Hubel U, Kirschner S, Gunther KP, Krummenauer F. [Long-term results in total knee arthroplasty: a meta-analysis of revision rates and functional outcomes] [in German]. Chirurg. 2011;82:618-624.

17. Mauerhan DR. Fracture of the polyethylene tibial post in a posterior cruciate-substituting total knee arthroplasty mimicking patella clunk syndrome: a report of 5 cases. J Arthroplasty. 2003;18:942-945.

18. Meding JB, Meding LK, Ritter MA, Keating EM. Pain relief and functional improvement remain 20 years after knee arthroplasty. Clin Orthop Relat Res. 2012;470:144-149.

19. Mestha P, Shenava Y, D'Arcy JC. Fracture of the polyethylene tibial post in posterior stabilized (Insall Burstein II) total knee arthroplasty. J Arthroplasty. 2000;15:814-815.

20. Minoda Y, Aihara M, Sakawa A, Fukuoka S, Hayakawa K, Tomita M, Umeda N, Ohzono K. Comparison between highly cross-linked and conventional polyethylene in total knee arthroplasty. Knee. 2009;16:348-351.

21. Muratoglu OK, Bragdon CR, O'Connor DO, Perinchief RS, Jasty M, Harris WH. Aggressive wear testing of a cross-linked polyethylene in total knee arthroplasty. Clin Orthop Relat Res. 2002;404:89-95.

22. Muratoglu OK, Mark A, Vittetoe DA, Harris WH, Rubash HE. Polyethylene damage in total knees and use of highly crosslinked polyethylene. J Bone Joint Surg Am. 2003;85(suppl 1):S7-13.

23. Naudie DD, Rorabeck CH. Sources of osteolysis around total knee arthroplasty: wear of the bearing surface. Instr Course Lect. 2004;53:251-259.

24. Noble PC, Conditt MA, Cook KF, Mathis KB. The John Insall Award: Patient expectations affect satisfaction with total knee arthroplasty. Clin Orthop Relat Res. 2006;452:35-43.

25. O'Rourke MR, Callaghan JJ. Goetz DD, Sullivan PM, Johnston RC. Osteolysis associated with a cemented modular posteriorcruciate-substituting total knee design: five to eight-year followup. J Bone Joint Surg Am. 2002;84:1362-1371.

26. Peters PC Jr, Engh GA, Dwyer KA, Vinh TN. Osteolysis after total knee arthroplasty without cement. J Bone Joint Surg Am. 1992;74:864-876.

27. Ries MD, Pruitt L. Effect of cross-linking on the microstructure and mechanical properties of ultra-high molecular weight polyethylene. Clin Orthop Relat Res. 2005;440:149-156.

28. Rodriguez JA, Bhende H, Ranawat CS. Total condylar knee replacement: a 20-year followup study. Clin Orthop Relat Res. 2001;388:10-17.

29. Rosner B. Fundamentals of Biostatistics. $5^{\text {th }}$ ed. Pacific Grove, CA: Duxbury; 1999:527-530.

30. Sharkey PF, Hozack WJ, Rothman RH, Shastri S, Jacoby SM. Insall Award paper: Why are total knee arthroplasties failing today? Clin Orthop Relat Res. 2002;404:7-13.

31. Stiehl JB, Komistek RD, Dennis DA, Paxson RD, Hoff WA. Fluoroscopic analysis of kinematics after posterior-cruciate-retaining knee arthroplasty. J Bone Joint Surg Br. 1995;77: 884-889.

32. Whaley AL, Trousdale RT, Rand JA, Hanssen AD. Cemented long-stem revision total knee arthroplasty. J Arthroplasty. 2003;18:592-599. 